\title{
Role of Pap's smear and visual inspection of cervix with Lugol's iodine for early detection of premalignant and malignant lesions of cervix: a cross sectional study
}

\author{
Kirtan M. Vyas ${ }^{1}$, Kalpesh S. Bhalodia ${ }^{2}$, Nilesh Thakor ${ }^{3 *}$ \\ ${ }^{1}$ Department of Obstetircs and Gynecology, PDU Medical College, Rajkot, Gujarat, India \\ ${ }^{2}$ Department of Obstetircs and Gynecology, Vardasn Hospital, Dhoraji, Gujarat, India \\ ${ }^{3}$ Department of Community Medicine, GMERS Medical College and Hospital, Gandhinagar, Gujarat, India
}

Received: 09 June 2016

Accepted: 01 July 2016

\section{*Correspondence:}

Dr. Nilesh Thakor,

E-mail: drnileshthakor@yahoo.co.in

Copyright: $\odot$ the author(s), publisher and licensee Medip Academy. This is an open-access article distributed under the terms of the Creative Commons Attribution Non-Commercial License, which permits unrestricted non-commercial use, distribution, and reproduction in any medium, provided the original work is properly cited.

\begin{abstract}
Background: Carcinoma of cervix is the third most frequently diagnosed cancer in Indian women. Carcinoma of cervix, due to its slow progression from pre-cancerous lesion to malignancy and easy accessibility to examination, gives us ample opportunity for early detection and thus considerably improved prognosis. To screen patients coming to GOPD at the age of 18-60 years by Pap smear and VILI and to detect specificity and sensitivity of each test for detecting CIN ( Cervical Intraepithelial Neoplasia) and Ca Cervix.

Methods: The present study was conducted in the Department of Obstetrics and Gynaecology, Smt. NHL Municipal Medical College and Hospital, Ahmedabad during October 2008 to October 2010. Total 50 women (18- 60 yrs) who fulfill selection criteria underwent pap smear and VILI. In pap smear and/or VILI positive patients, cervical biopsy and histopathological examination were done. The sensitivity and specificity of each test were determined and compared.

Results: Out of total 50 women, 20 (40\%) women were in the age group of $30-39$ years. $64 \%$ women had coitage before 20 years. $56 \%$ of the women had 3 or more children. $74 \%$ of the patients came with chief complaint of vaginal discharge followed by lower abdominal pain in $10 \%$ of the patients. On visual inspection with lugol's iodine (VILI), squamo-columnar junction was seen in $66 \%$ of the women. Out of 50 women, $5(10 \%)$ women tested positive for cytology results. Out of 50 Women, 8 (16\%) women came out to be VILI test positive. The sensitivity, specificity, positive predictive value and negative predictive value for VILI test are $80 \%, 91.11 \%, 50 \%, 97.6 \%$ respectively. The sensitivity, specificity, positive predictive value and negative predictive value for Pap test are $80 \%, 97 \%, 80 \%, 97 \%$ respectively.

Conclusions: VILI has almost equal sensitivity as compared to Pap (Cytology) test but Pap (Cytology) test has higher specificity compared to VILI.
\end{abstract}

Keywords: VILI, Pap test, CIN, Carcinoma of cervix, Cytology

\section{INTRODUCTION}

According to World Health Organization, cervical cancer is the second most common type of cancer among females and approximately more than 2, 50, 000 deaths occur every year worldwide. Carcinoma of cervix is the third most frequently diagnosed cancer in Indian women.
In India more than 120,000 new cases of cervical cancer are detected each year and nearly 75,000 women die annually from the disease. ${ }^{1}$

In many developing countries, it is the most common cancer among women and the most common cause of death among middle aged women. These are the women 
who are needed most in family. Despite of its public health importance there is no effective prevention programme in most of the developing countries and hence the risk of disease and death from cervical cancer remains largely uncontrolled. ${ }^{2}$

Carcinoma of cervix, due to its slow progression from pre-cancerous lesion to malignancy and easy accessibility to examination, gives us ample opportunity for early detection and thus considerably improved prognosis. Early detection may be through opportunistic examination of women attending outpatient clinics or through systematic programme of screening. Hence, one simple low technique screening tests namely visual inspection with Lugol's iodine (VILI) which is based on the ability of the trained health care personnel to detect yellow non iodine uptake areas in the cervical transformation zone are currently being evaluated in the experimental setting as potential alternative to cervical cytology. So, the present study is done to screen patients coming to GOPD at the age of 18-60 years by Pap smear and VILI and to detect specificity and sensitivity of each test for detecting CIN and Ca Cervix by comparing with the histology from positively screened women in all two.

\section{METHODS}

The present study was conducted in the Department of Obstetrics and Gynaecology, Smt. NHL Municipal Medical College and Hospital, Ahmedabad between October 2008 to October 2010 at GOPD. This was a Cross sectional study conducted in 50 women (18-60 years) who fulfil selection criteria after taking proper consent. The average number of women who attended GOPD was 60 per day. Among them, women who fulfilled selection criteria were randomly selected. Inclusion criteria - Patient in age group (18-60 years) were taken into study and priority was given to patients having following risk factor: early marriage, early pregnancy (teenage pregnancy), sexual activity at early age, multiparity, multiple sexual partners, women with sexually transmitted disease (STD), leucorrhea, abnormal vaginal bleeding. Unmarried patient, patients with bleeding per vagina $(\mathrm{P} / \mathrm{V})$ and active infection at the time of examination, women with frank invasive cervical cancer were excluded from the study. Pap smear positive cases were considered as CIN 1 or above. VILI was considered to be positive on detection of yellow iodine non non uptake areas in the transformation zone or close to touching squamo columnar junction. The positive cases were sent for biopsies and histological evaluation. The results are expressed in tables and percentage. The sensitivity and specificity of each test are determined and compared by using Graph Pad InStat 3 version of software.

\section{RESULTS}

Out of total 50 women, $20(40 \%)$ women were in the age group of 30-39 years. Majority of the women (42\%) were having high school education. $64 \%$ women had coitage before 20 years. $56 \%$ of the women had 3 or more children. $74 \%$ of the patients came with chief complaint of vaginal discharge followed by lower abdominal pain in $10 \%$ of the patients. On visual inspection with lugol's iodine (VILI), squamo-columnar junction was seen in $66 \%$ of the women (Table 1 ).

Table 1: Visual examination with Lugol's iodine.

\begin{tabular}{|ll|}
\hline $\begin{array}{l}\text { Visual Examination with } \\
\text { Lugol's Jodine }\end{array}$ & $\begin{array}{l}\text { Number of women } \\
\text { (Percentages) }\end{array}$ \\
\hline $\begin{array}{l}\text { Squamous columnar } \\
\text { junction fully seen }\end{array}$ & $33(66 \%)$ \\
\hline Cervical polyp & $4(8 \%)$ \\
\hline Nabothian follicles & $4(8 \%)$ \\
\hline Cervicitis & $5(10 \%)$ \\
\hline Erosion & $4(8 \%)$ \\
\hline
\end{tabular}

Out of 50 women, 5 women tested positive for cytology results. 1 woman had ASCUS (Atypical Squamous Cells of Undetermined Significance), 1 woman had LSIL (Low grade Squamous Intraepithelial Lesion) and 3 women had HSIL (High grade Squamous Intraepithelial Lesion). 45 women tested negative for cytology results. One women was reported ASCUS which on histology turned out to be negative for pre malignant lesion or malignancy. One women was reported as smear report negative for intraepithelial lesion or malignancy, which on biopsy showed CIN1 respectively. 4 women which were reported as having premalignant lesion or malignancy by conventional cytology were later on confirmed on histology (Table 2).

Table 2: Conventional cytology results.

\begin{tabular}{|ll|}
\hline Cytology results & Number of women (Percentage) \\
\hline Positive & $5(10 \%)$ \\
\hline Negative & $45(90 \%)$ \\
\hline True Positive & $4(8 \%)$ \\
\hline True Negative & $44(88 \%)$ \\
\hline False Positive & $1(2 \%)$ \\
\hline False Negative & $1(2 \%)$ \\
\hline
\end{tabular}

Out of 50 women, 8 women came out to be VILI test positive. 42 women were VILI test negative. Out of 8 women tested positive for VILI test, 4 women were having false positive result. False positive result were due to false interpretation of erosion, cervicitis, infection with trichomonas vaginitis. One woman tested false negative because in post-menopausal woman squamo columnar junction ascends into cervical canal, leading to false negative test. 41 women had true negative test as their conventional cytology reports were negative. (Table 3) In the present study sensitivity, specificity, positive predictive value and negative predictive value for VILI test are $80 \%, 91.11 \%, 50 \%, 97.6 \%$ respectively. (Table 4) In the present study comparison was done among Pap smear and VILI with histopathology. VILI has almost 
equal sensitivity as compared to Pap (Cytology) test but Pap (Cytology) test showed higher specificity compared to VILI (Table 5).

Table 3: VILI test results.

\begin{tabular}{|ll|}
\hline Cytology results & Number of women $(\%)$ \\
\hline Positive & $8(16 \%)$ \\
\hline Negative & $42(84 \%)$ \\
\hline True positive & $4(8 \%)$ \\
\hline True negative & $41(82 \%)$ \\
\hline False positive & $4(8 \%)$ \\
\hline False negative & $1(2 \%)$ \\
\hline
\end{tabular}

Table 4: Statistics of VILI test results.

\begin{tabular}{|ll|}
\hline Sensitivity (\%) & 80 \\
\hline Specificity (\%) & 91.11 \\
\hline Positive predictive value (\%) & 50 \\
\hline Negative predictive value (\%) & 97.6 \\
\hline
\end{tabular}

Table 5: Statistics of VILI test results.

\begin{tabular}{|ll|}
\hline Sensitivity (\%) & 80 \\
\hline Specificity (\%) & 91.11 \\
\hline Positive Predictive Value (\%) & 50 \\
\hline Negative Predictive Value (\%) & 97.6 \\
\hline
\end{tabular}

Table 6: Comparison of Pap test and VILI test.

\begin{tabular}{|ll|l|}
\hline Name of Test & Pap Test & VILI Test \\
\hline Sensitivity (\%) & 80 & 80 \\
\hline Specificity (\%) & 97 & 91.11 \\
\hline Positive Predictive Value (\%) & 80 & 50 \\
\hline Negative Predictive Value (\%) & 97 & 97.6 \\
\hline
\end{tabular}

\section{DISCUSSION}

The factors responsible for higher incidence of CIN and ca cervix were poor personal hygiene, poor living condition, illiteracy, unstable marriage, early age at first intercourse. Duration of marriage and duration of exposure to sexual intercourse has an important role in the genesis of cervical dysplasia. In our study, $64 \%$ women had coitage before 20 years. In our study positive results obtained from pap smear were $16 \%$. Sensitivity of pap smear was found to be low $-80 \%$ compared to specificity which was $97 \%$. This was attributed to high number false negative smear. The Sensitivity and specificity of the Pap test in Londhe $\mathrm{M}$ et al was $13.2 \%$ and $96.3 \%$, in Sankaranarayanan $\mathrm{R}$ et al was $29.5 \%$ and $92.3 \%$, in Gosh P et al was $52.6 \%$ and $99 \%$ and in Shuchi et al was $84.2 \%$ and $62.1 \%$ respectively. ${ }^{3-6}$ In our study VILI was positive in $16 \%$ cases. Sensitivity of VILI was found to be $80 \%$ compared to specificity which was $91.11 \%$. The Sensitivity and specificity of the VILI test in in Sankaranarayanan R et al was $85.4 \%$ and $91.7 \%$, in Gosh $\mathrm{P}$ et al was $93.3 \%$ and $100 \%$, in Shuchi et al was $75.9 \%$ and $89.5 \%$ and in Samir Khan et al was $74.4 \%$ and $78.9 \%$ respectively. ${ }^{4-7}$

\section{CONCLUSION}

From the results of this study, it has been concluded that VILI has almost equal sensitivity as compared to Pap (Cytology) test but Pap (Cytology) test has higher specificity compared to VILI. Thus by combining VILI along with Pap smear we can maximize the sensitivity and specificity of cancer cervix screening, which are more cost effective and practically implementable.

Funding: No funding sources

Conflict of interest: None declared

Ethical approval: The study was approved by the Institutional Ethics Committee

\section{REFERENCES}

1. Hakama M, Chamberlain J, Day NE, Miller AB, Prorok PC. Evaluation of screening programmes for gynaecological cancer. Br J Cancer. 1985;52:669-73.

2. Kushtagi P, Fernandes P. Significance of persistant inflammatory cervical smears in sexually active women of reproductive age. J Obstet Gynaecol. 2002;52(1):124-6.

3. Londhe M, George SS, Seshadri L. Detection of CIN by naked eye visualization after application of acetic acid. Indian J Cancer. 1997;34(2):88-91.

4. Sankaranarayanan R, Shastri SS, Basu P, Mahé C, Mandal R, Amin G, Roy C, et al. The role of low level magnification in visual inspection with acetic acid for the early detection of cervicalneoplasia. Cancer Detect Prev. 2004;28(5):345-51.

5. Ghosh P, Gandhi G, Kochhar PK, Zutshi V, Batra S. Visual inspection of cervix with lugol's iodine for early detection of premalignant and malignant lesions of cervix. Indian $J$ Med Res. 2012;136(2):265-71.

6. Consul S, Agrawal A, Sharma H, Bansal A, Gutch M, Jain H. Comparative study of effectiveness of pap smear versus visual inspection with acetic acid and visual inspectionwith lugol's iodine for mass screening of premalignant and maligmant lesion of cervix. Indian J Med Paediatr Oncol. 2012;33(3):161-5.

7. Khan S, Jha R. Accuracy of cytology, visual inspection with acetic acid or lugol's iodine in cervical cancer screening. Nepal $\mathbf{J}$ of Obstetrics and Gynaecology. 2007;2(2):48-53.

Cite this article as: Vyas KM, Bhalodia KS, Thakor N. Role of Pap's smear and visual inspection of cervix with Lugol's iodine for early detection of premalignant and malignant lesions of cervix: a cross sectional study. Int J Reprod Contracept Obstet Gynecol 2016;5:2684-6. 